\title{
Avaliação Da Efetividade Do STAR - Programa De Treinamento De Equipes De Instituições De Longa Permanência Para Idosos - Na Versão Para A Língua Portuguesa Do Brasil
}

\section{Resumo}

\author{
Dalpai, D.; Reis, R.C.; Camozzato, A.; \\ Apresentador: Débora Dal Pai \\ Trabalho Premiado - $3^{\circ}$ Lugar
}

Introdução: O treinamento dos cuidadores de idosos com demência é uma das intervenções recomendadas para o tratamento de sintomas psicológicos e comportamentais da demência (SPCD). Staff Training for Assisted Living Residences (STAR) é um programa de treinamento de equipes de instituições de longa permanência para idosos, porém, há necessidade de validação da versão para a língua portuguesa do Brasil. Diante disso, o objetivo deste estudo consiste em avaliar a efetividade do STAR na redução dos SPCD e do desgaste dos cuidadores e no aperfeiçoamento das habilidades de manejo destes sintomas por parte da equipe. Método: este foi um ensaio clínico controlado não randomizado. Os SPCD foram quantificados pelo Inventário Neuropsiquiátrico (NPI). A escala de desgaste do NPI (NPI-D) e o Inventário de Sobrecarga de Zarit (ZBI) quantificaram o desgaste que os sintomas dos residentes causam aos cuidadores e a Escala de Estratégias de Gerenciamento da Demência (EEGD) avaliou o incremento nas habilidades de manejo dos cuidadores. Foram avaliados 22 residentes com SPCD e 17 cuidadores. O teste t de Student para medidas repetidas ou o teste de Wilcoxon foram usados para comparar os grupos. A ANOVA de medidas repetidas com ajustamento foi usada para controlar o efeito de covariáveis. Resultados: o NPI (frequência $\mathrm{x}$ gravidade) não diferiu entre os grupos na análise não ajustada. Depois do ajuste para educação do residente houve uma melhora significativa $(p=0,048)$ no grupo intervenção, com um Eta ao quadrado parcial de 0,181 . Quanto menor o nível educacional, mais benéfico foi o treinamento. Os escores de NPI-D, ZBI e EEGD não diferiram entre os grupos intervenção e controle. Conclusões: o STAR foi parcialmente efetivo na redução dos SPCD em uma amostra brasileira e não apresentou efeitos no desgaste e no incremento nas habilidades de manejo dos cuidadores. Efeito de diluição, não cegamento e seguimento curto podem ter limitado os resultados.

\section{Referência:}

Dalpai, D.; Reis, R.C.; Camozzato, A.; Avaliação Da Efetividade Do STAR - Programa De Treinamento De Equipes De Instituições De Longa Permanência Para Idosos - Na Versão Para A Língua Portuguesa Do Brasil. In: II Congresso Brasileiro de Medicina Hospitalar - II CBMH [= Blucher Medical Proceedings, vol.1, num.5] São Paulo: Editora Blucher, 2014. p.3 DOI 10.5151/medpro-II-cbmh-021 